\title{
Avaliação de Amortecedores Veiculares Remanufaturados Segundo Alguns Critérios da Norma ABNT NBR 13308
}

\author{
Luciano Pisanu $^{1 *}$, Lilian L. N. Guarieiro ${ }^{1}$; Ailton B. J. Soares ${ }^{1}$; Matheus de O. Barreto ${ }^{1}$; \\ Raphael F. Rezende ${ }^{1}$; José Roberto Turrini ${ }^{2}$ \\ ${ }^{1}$ Faculdade Senai Cimatec, Salvador - BA \\ ${ }^{2}$ Jorotu - Automotive Consulting \\ Email: 1pisanu@fieb.org.br, lilian.guarieiro@fieb.org.br, ailtonsj@ fieb.org.br, \\ matheus.barreto@fieb.org.br, raphael.rezende@fieb.org.br; jturrini@gmail.com
}

\section{RESUMO}

Atualmente, são produzidos no mundo cerca de 80 a 90 milhões de carros por ano, sem contar caminhões, trens, ônibus, motos e bicicletas. Tais veículos utilizam amortecedores no seu sistema de suspensão, de modo que somado a frota circulante são fabricados mais de 400 milhões de amortecedores /ano . O aumento crescente de veículos comercializados, e a conseqüente necessidade de manutenção do sistema da suspensão destes veículos se refletem cada vez mais no aumento do número de empresas especializadas em remanufatura e recondicionamento de amortecedores. Assim, o objetivo deste trabalho foi avaliar amortecedores remanufaturados, segundo orientações da Norma ABNT NBR 13308 (Veículos rodoviários automotores - Amortecedor de suspensão - Verificação de desempenho e durabilidade - Método de ensaio), comparando os resultados obtidos com avaliações de amortecedores similares novos. Neste estudo, foi priorizado o ensaio de resistência à corrosão (ABNT NBR 8094 - Ensaio de corrosão por exposição à névoa salina) e o ensaio de verificação de bloqueio hidráulico. Foram avaliados quatro amortecedores remanufaturados e 4 amortecedores originais de um fabricante do Mercosul, totalizando 8 amostras de teste. Os amortecedores foram avaliados quanto à qualidade da pintura e acabamento superficial após exposição à corrosão acentuada e o comportamento quando submetidos ao ensaio de bloqueio hidráulico. Após a análise dos resultados dos ensaios, foram verificados que ambos os grupos de amortecedores não resistiram à exposição de névoa salina, apresentando mais de 10 pontos de corrosão, com comprometimento de mais de 5\% da área externa. Também se observou no gráfico de força por deslocamento que nas 4 amostras remanufaturadas ocorreu bloqueio hidráulico seguido de vazamento de óleo pela sede da haste. Contudo, nas amostras originais não foi observada ocorrência de falha. 


\section{INTRODUÇÃO}

No final do século XIX, os veículos automotores eram considerados inseguros, sem conforto e sem estabilidade devido à falta de absorvedores de impacto e à baixa qualidade das estradas. Naquela época, a falta dos amortecedores trazia inúmeros transtornos ao motorista, tornando os veículos instáveis pelas irregularidades do solo [1]. Assim, o motorista perdia facilmente o controle nas curvas, pela falta de compensação da inclinação do veículo. Outro inconveniente da falta de um sistema de amortecimento era o excesso de vibração transmitido à carroceria durante a rodagem do veículo e a constante troca de pneus, pelo intenso impacto que estes sofriam. Em 1926, uma empresa americana laçou os primeiros sistemas para eliminar vibrações e, a partir deste evento houve uma evolução significativa e diversificada de amortecedores [1]. Atualmente, encontra-se no mercado amortecedores para as mais diversas aplicações, ou seja, para equipar veículos de passeio, de carga e, os destinados às exigências mais extremas como veículos de corrida e rali. O amortecedor é um dos principais elementos que compõem o sistema de suspensão de um veículo e responsável pelas características de barulho, vibração e aspereza (NVH - do inglês: noise, vibration, harshness). Suas principais funções são: controlar, reduzir e estabilizar o movimento de vai-e-vem da mola [2], que é estendida e comprimida ao ponto máximo quando os pneus passam por buracos e ondulações mais severas, compensando o efeito de impacto da estrada, mantendo o alinhamento correto do veículo, dirigibilidade e aderência ao pavimento [1].

Segundo o levantamento feito pelo Sindicato Nacional da Indústria de Componentes para Veículos Automotores (Sindipeças) [3] nos últimos 10 anos a frota brasileira cresceu de 21.366.485 milhões para 38.025.799 milhões (um aumento de $~ 78 \%$ ), e indica que a frota circulante brasileira cresceu 7,5\% em 2012. O número total de veículos produzidos nos últimos 10 anos cresceu de 1,6 milhões para 3,3 milhões por ano. Estes números refletem diretamente na produção de autopeças, como os amortecedores de suspensão, objeto deste estudo, o que pode fomentar o mercado paralelo de reposição e falsificação de componentes automotivos. De um modo geral, alguns fabricantes de amortecedores preveem que as ocorrências de falhas nos amortecedores iniciam-se próximo a $30.000 \mathrm{~km}$ de rodagem do veículo e, se acentuam na faixa de 75 a $120.000 \mathrm{~km}$. Após $120.000 \mathrm{~km}$ ocorre uma estabilidade, até aproximadamente $170.000 \mathrm{~km}$, onde a taxa de falha retorna com ocorrências acentuadas. Algumas empresas fabricantes recomendavam a troca preventiva dos seus componentes com $40.000 \mathrm{~km}$ rodados, como uma maneira de preservar a confiabilidade de sua marca com uma taxa de falha abaixo de $10 \%$. Atualmente, sabe-se que a durabilidade dos amortecedores está diretamente ligada com a severidade de uso do veículo e condições de pista, fato este que é amplamente divulgado por revistas especializadas do setor automotivo.

Segundo Azuaga (2000 apud Bastos, 2011, p. 63) [4] alguns estudos brasileiros, voltados para questões ambientais de análises de emissões veiculares, realizaram estimativas globais das quilometragens anuais percorridas pela frota nacional. Dados obtidos nestes estudos evidenciaram que ocorre um declínio da distância percorrida pela idade do veículo, sendo que nos primeiros dois anos o motorista roda mais de $40.000 \mathrm{~km}$. De uma maneira geral, este comportamento pode ser explicado no fato que aos proprietários dos veículos mais novos possuem maior disponibilidade de renda para o consumo de combustíveis [5]. Como já citado neste trabalho, considerando o início da ocorrência de falhas a partir dos $30.000 \mathrm{Km}$, teoricamente, a partir do segundo ano de uso do veículo novo, este já estaria entrando na faixa de substituição dos amortecedores. 
Considerando as trocas de amortecedores para carros novos, nas condições mais severas de uso e, a necessidade de manutenção da frota circulante, existe um volume muito significativo de amortecedores danificados para o mercado de reposição atender. Esta realidade de consumo crescente de peças de reposição tem fomentado o crescimento de empresas de remanufatura de amortecedores. $\mathrm{O}$ fato mais preocupante é que este crescimento desordenado pode levar as pequenas empresas a se aventurarem neste mercado sem o mínimo de critérios. Este fato poderá refletir no risco a segurança do motorista, sem falar nos prejuízos financeiros advindos da utilização de uma peça que não atende os critérios de desempenho, exigido pelos veículos e normas vigentes. Para coibir o aumento de peças de reposição de baixa qualidade foi publicada pelo INMETRO a Portaria n. ${ }^{\circ} 301$ de 21 de julho de 2011[6]. Esta portaria obriga os fabricantes e importadores de componentes automotivos, dentre eles amortecedores de suspensão, a iniciarem o processo de certificação. Assim como as peças originais, os componentes para reposição devem ser produzidos dentro dos pré-requisitos das montadoras, atendendo às normas e especificações de qualidade internacionais, bem como às demandas e criticidades do veículo. Para fornecer componentes à indústria automobilística, as empresas devem seguir rigorosos processos de qualidade, além de possuírem certificação [7]. Neste contexto, o objetivo deste trabalho foi realizar um estudo comparativo entre amortecedores novos e remanufaturados, baseando-se em dois critérios de aceitação da norma da ABNT NBR 13308[8]: resistência à corrosão e bloqueio hidráulico.

\section{MATERIAIS E MÉTODOS}

\subsection{Amostras Utilizadas nos Ensaios}

As amostras novas utilizadas no estudo comparativo de amortecedores, segundo alguns critérios da norma ABNT NBR 13308, foram fabricadas por uma empresa de componentes automotivos do MERCOSUL. As amostras recondicionadas de um fabricante não identificado foram adquiridas no mercado de reposição de autopeças. Assim, foram avaliadas 4 amostras de amortecedores novos e outras 4 de amortecedores remanufaturados nos ensaios de corrosão e bloqueio hidráulico. Os amortecedores avaliados foram os dianteiros do veículo nacional Fiat Pálio e receberam identificação de acordo com os códigos presentes Tabela 1.

\section{Tabela 1. Código das amostras de amortecedores}

\begin{tabular}{lc}
\hline Amortecedor & Código \\
\hline Remanufaturado 1 & REC 1 \\
Remanufaturado 2 & REC 2 \\
Remanufaturado 3 & REC 3 \\
Remanufaturado 4 & REC 4 \\
Novo 1 & $\mathrm{N} 1$ \\
Novo 2 & $\mathrm{N} 2$ \\
Novo 3 & $\mathrm{N} 3$ \\
Novo 4 & $\mathrm{N} 4$ \\
\hline
\end{tabular}




\subsection{Ensaio de Resistência a Corrosão (Salt Spray)}

Inicialmente, todas as amostras foram submetidas ao ensaio de corrosão (Salt Spray), por este não causar interferências no ensaio de verificação de bloqueio hidráulico. O ensaio de Salt Spray ou névoa salina é um ensaio comparativo muito importante na área de corrosão, pois verifica a qualidade de um material metálico, com ou sem proteção, contra a corrosão. $\mathrm{O}$ ensaio de corrosão acelerada foi realizado com uma Câmara de Ensaio Cíclico (EQUILAM Modelo CCT-MP-LQ-03/2009), utilizando como instrumentação um medidor de pH (Modelo PHS-B3) e um medidor de condutividade (QUIMIS - Modelo Q405M), seguindo as instruções presentes na especificação ABNT NBR 8094 [9] e ABNT NBR 13308. A especificação ABNT 13308 apresenta a norma de ensaio NBR 8094 como referência para a realização do teste utilizando solução de cloreto de sódio durante 48 horas. Assim, foi estabelecido o requisito de aceitação no ensaio de névoa salina o amortecedor que resistir a este procedimento, sendo permitidos no máximo 10 pontos de corrosão no amortecedor, desde que não ultrapasse a 5\% da área externa do mesmo. A Figura 1 apresenta os amortecedores na câmara úmida de ensaio cíclico antes de serem submetidos ao ensaio.

\section{Figura 1. Amostras de amortecedor na câmara úmida.}

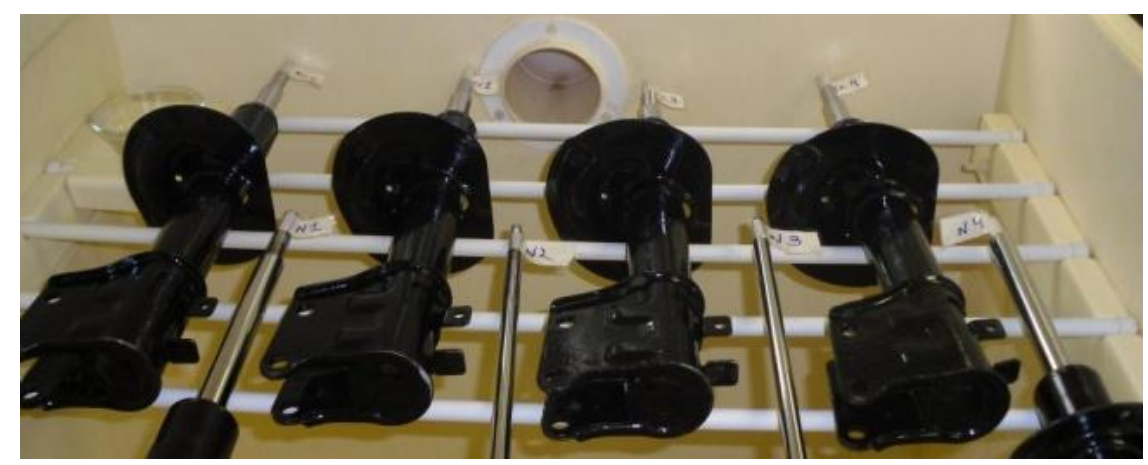

Antes de dar inicio ao ensaio de resistência a corrosão, os corpos de prova utilizados no ensaio foram limpos adequadamente. Na câmara úmida utilizada para o teste, uma solução aquosa de aproximadamente $5 \%$ de cloreto de sódio $(\mathrm{NaCl})$, preparada pela dissolução de 50 $\pm 5 \mathrm{~g}$ de $\mathrm{NaCl}$ para um litro de solução (preparada com água destilada), foi dispersa na forma de névoa com auxilio do bico dispersor, criando um ambiente corrosivo no interior da câmara. Assim, as amostras em teste foram submetidas a um ataque químico acelerado. As amostras foram ensaiadas durante 48 horas, conforme prescrito em norma, com avaliação após o final do teste. $\mathrm{O}$ ensaio foi realizado em ambiente climatizado a uma temperatura de $23+/-2^{\circ} \mathrm{C}$ e umidade relativa do ar de $50+/-5 \%$. Após o término do ensaio todas as amostras foram lavadas em água corrente nas regiões onde houve afloramento de produto de corrosão, na região dos contornos das peças e em regiões soldadas. Foi retirada a tinta em alguns cordões soldadas, com a finalidade de observar se houve migração subcutânea da corrosão, bem como seu avanço. 


\subsection{Ensaios de Verificação de Bloqueio Hidráulico}

O ensaio de verificação de Bloqueio Hidráulico foi realizado com o intuito de verificar a ocorrência de calço hidráulico na fase de compressão do amortecedor. Os dados dos ensaios foram coletados em um equipamento MTS FlexTest 100 (Station Manager Version 5.1A 2572), utilizando o software Multi Purpose Test Ware (MPT-Version 5.1A 2572) e um atuador hidráulico de $25 \mathrm{kN}$ (A4). Foram também utilizados nos ensaios uma célula de carga de $25 \mathrm{kN}$ (CC-04), um transformador linear diferencial variável (LVDT PS-04) e controlador digital de temperatura (Novus N480). As amostras foram lavadas com água e sabão neutro para garantir a ausência de óleo na parte externa do amortecedor e logo após foram montadas no dispositivo de ensaio (Figura 2).

\section{Figura 2. Dispositivo de fixação do amortecedor.}

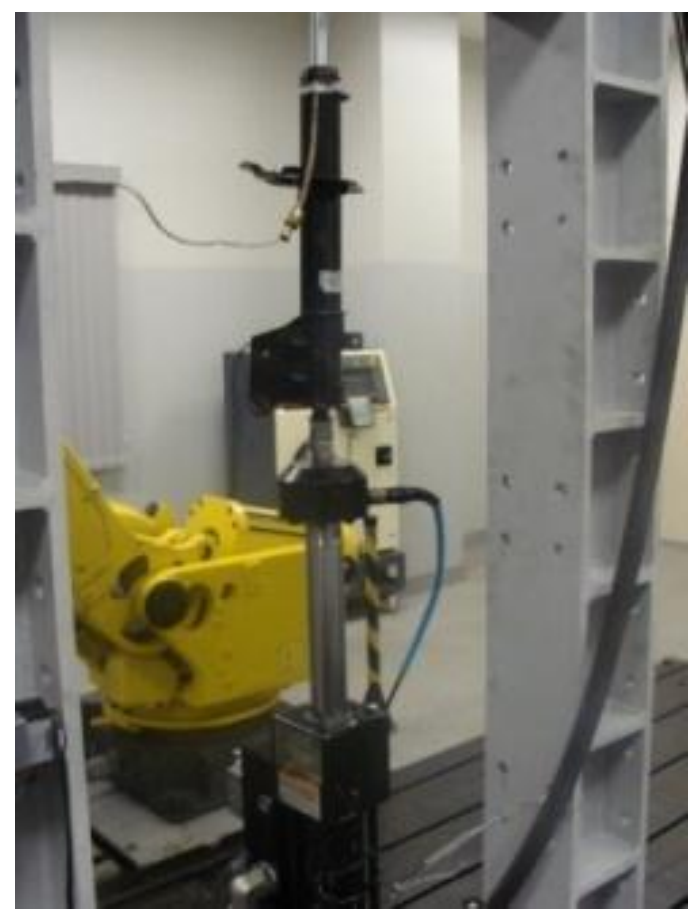

Na região próxima a guia da haste foi fixado um termopar (PT100) para medição da temperatura. As amostras foram acopladas nos dispositivos de ensaios, na posição de $60 \mathrm{~mm}$ antes do curso de fechamento total (para garantir que o curso de trabalho atingisse $10 \mathrm{~mm}$ antes do fechamento total do amortecedor).

Para garantir a eficácia e padronização dos ensaios, todos os instrumentos utilizados na execução dos ensaios foram calibrados. Os ensaios de bloqueio hidráulico foram realizados em três diferentes temperaturas $\left(30,60\right.$ e $\left.90^{\circ} \mathrm{C}\right)$. Não foi possível obter resultados na temperatura de $120^{\circ} \mathrm{C}$, pois a execução do ensaio atingiu o tempo máximo de 30 minutos prevalecendo sobre o segundo critério que e o de alcançar $140^{\circ}$ antes do tempo limite de execução do ensaio. 


\section{RESULTADOS E DISCUSSÃO}

\subsection{Testes de Resistência a Corrosão}

Através dos resultados obtidos no ensaio de resistência a corrosão pode-se destacar que, para os amortecedores novos (N1; N2; N3 e N4) no cordão de solda não foram observados processo de corrosão, apenas alguns pontos de corrosão no topo da haste metálica, sem interferência no curso de atuação. As amostras novas apresentaram formação de produtos de corrosão, porém bem menos intenso que as amostras recondicionadas, caracterizando melhor proteção do revestimento (processo de pintura e acabamento superficial). A Figura 3 apresenta fotos de algumas amostras, onde pode ser observado o efeito da corrosão nas amostras remanufaturadas (Figuras $3 \mathrm{a}$ e $3 \mathrm{~b}$ ) e em uma amostra de amortecedor novo (Figura $3 \mathrm{c})$.

Figura 3. Fotos de algumas amostras de amortecedores utilizados no ensaio de resistência a corrosão. (a) amostra REC 1; (b) amostra REC 3; (c) amostra N4.
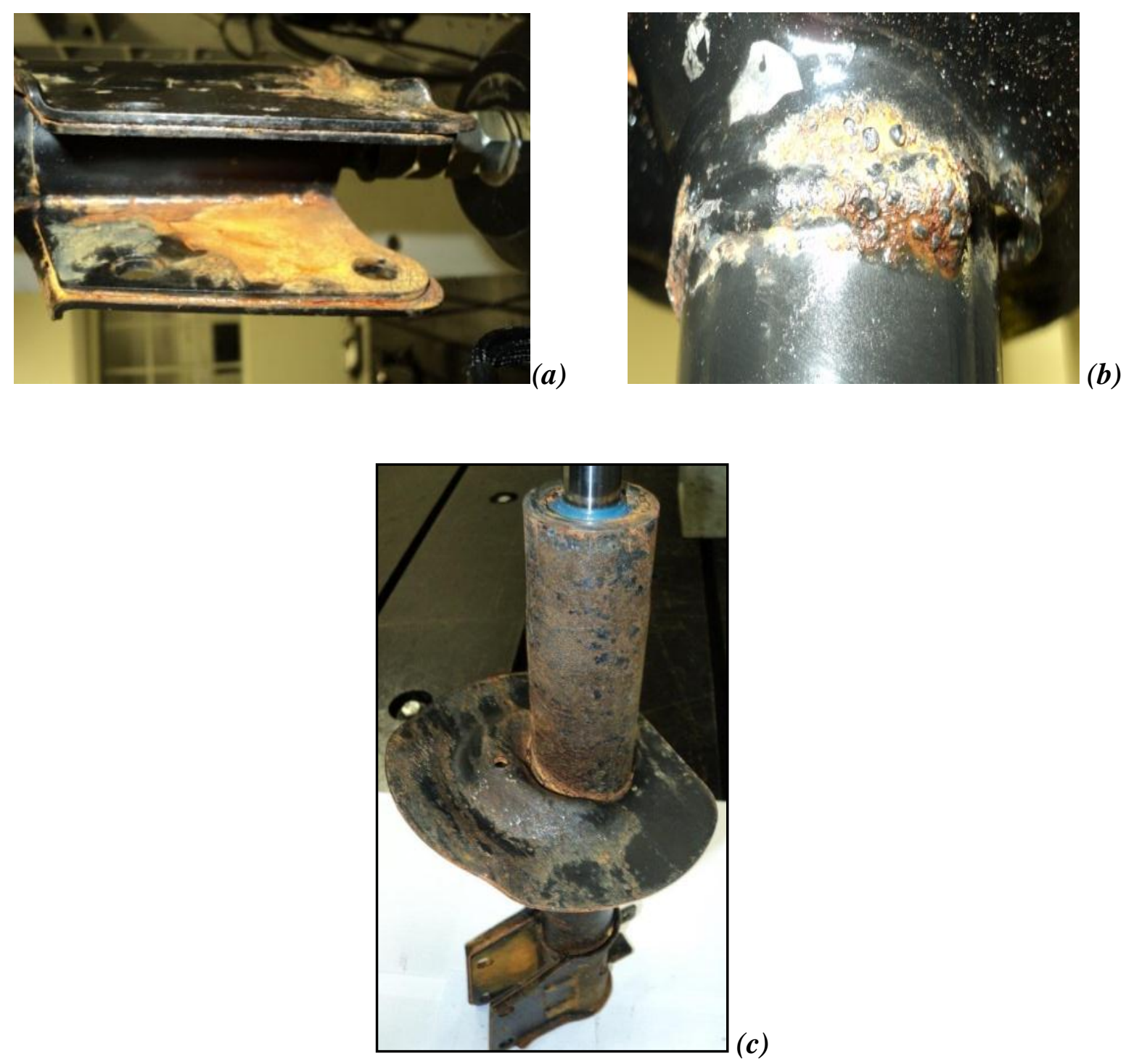
Contudo, as amostras de amortecedores recondicionados podem ser observados resultados significativos quanto a resistência a corrosão. Assim, as amostras REC 1 (Figura 3a) e REC 4 apresentaram formação de produtos de corrosão de forma mais intensa na borda da peça, com um avanço de corrosão em torno de $3 \mathrm{~mm}$. Nas regiões soldadas da amostra REC 3 (Figura $3 b$ ), o processo de corrosão foi semelhante ao ocorrido nas bordas, sendo que o avanço de corrosão nesta região ficou em torno de $8 \mathrm{~mm}$. Apesar das amostras de amortecedores novos serem menos atacadas pela corrosão, nenhum dos amortecedores foi aprovado segundo requisitos deste item da norma.

$\mathrm{O}$ pH da solução coletada, após a pulverização a $35^{\circ} \mathrm{C}$, apresentou um valor na faixa de 6,5 a 7,2 determinado através de um instrumento medidor de $\mathrm{pH}$.

\subsection{Ensaio de Bloqueio Hidráulico}

As curvas obtidas no ensaio de bloqueio hidráulico das amostras de amortecedores remanufaturados a 30 e $60{ }^{\circ} \mathrm{C}$. estão apresentadas respectivamente nas Figura 4 e 5.

Figura 4. Comparativo dos resultados obtidos no ensaio de bloqueio hidráulico a $30{ }^{\circ} \mathrm{C}$ para as amostras recondicionadas.

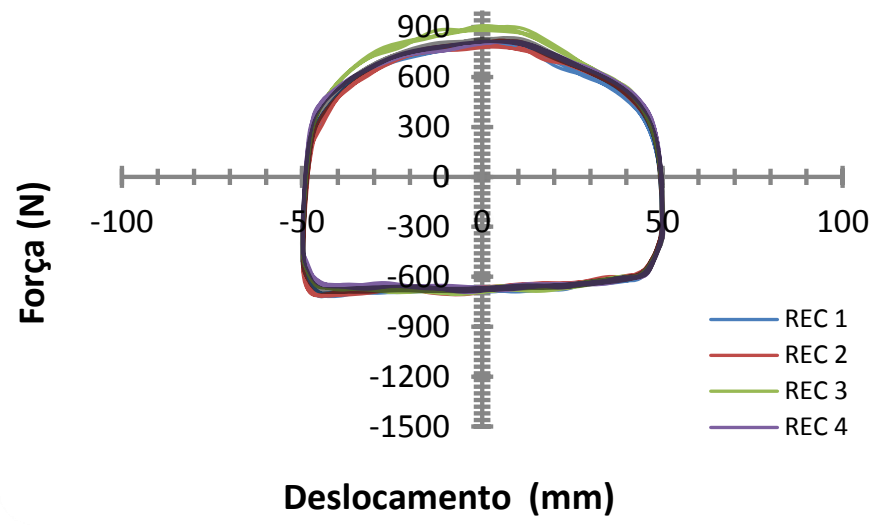

Analisando as curvas de desempenho, presentes na Figura 4, podemos visualizar a uniformidade das amostras REC 2, REC 3, REC 4 com valores em torno de $700 \mathrm{~N}$ na compressão e $800 \mathrm{~N}$ na extensão. A amostra REC 1 apresentou um comportamento similar as outras amostras remanufaturadas na fase de compressão e um pico próximo a $900 \mathrm{~N}$ na fase de extensão (tração).

$\mathrm{Na}$ análise das curvas a $60^{\circ} \mathrm{C}$ pôde-se observar que as amostras REC 1 e REC 2, nesta condição, obtiveram um desempenho similar, sendo que no início da fase de compressão ambas as amostras apresentaram um resultado de força próximo a $400 \mathrm{~N}$ com progressão para $700 \mathrm{~N}$, a partir da posição de $20 \mathrm{~mm}$ (Figura 5). Tais resultados sugerem a ocorrência de uma bolsa de ar no início da compressão e, consequente, início da formação de um pico no final desta fase. A amostra REC 3 teve comportamento similar, porém com aumento da força de compressão a partir da posição 40mm. Entretanto a amostra REC 4 obteve um comportamento mais estável, quando comparado à operação normal de um amortecedor. Nesta temperatura pôde ser observado claramente a ocorrência de bloqueio hidráulico na amostra REC 2 e início de formação do pico nas demais amostras remanufaturadas. 
Figura 5. Comparativo dos resultados obtidos no ensaio de bloqueio hidráulico a $60{ }^{\circ} \mathrm{C}$ para as amostras recondicionadas.

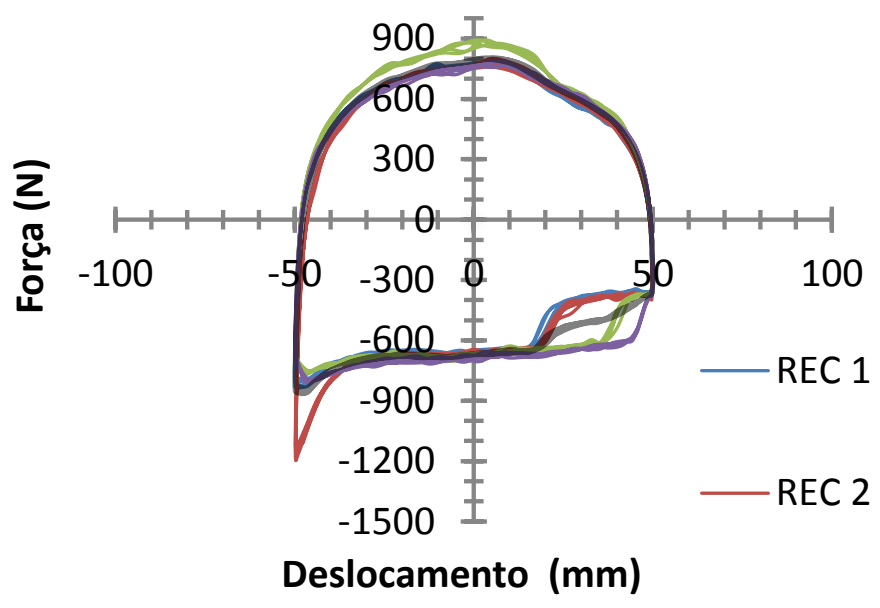

O resultado obtido no ensaio de bloqueio hidráulico a $90^{\circ}$ foi discutido somente para a amostra REC 1, pois foi a única que atingiu a temperatura solicitada sem rompimento do selo. Assim, através da Figura 6, pode-se observar que a amostra REC 1 apresentou perda notória de desempenho a $90^{\circ} \mathrm{C}$ e apresentou vazamento de óleo, devido ao rompimento do selo na mesma temperatura aos 19 min e 37 s corridos do ensaio.

Figura 6. Curva obtida no ensaio de bloqueio hidráulico a $90^{\circ} \mathrm{C}$ para a amostra REC 1.

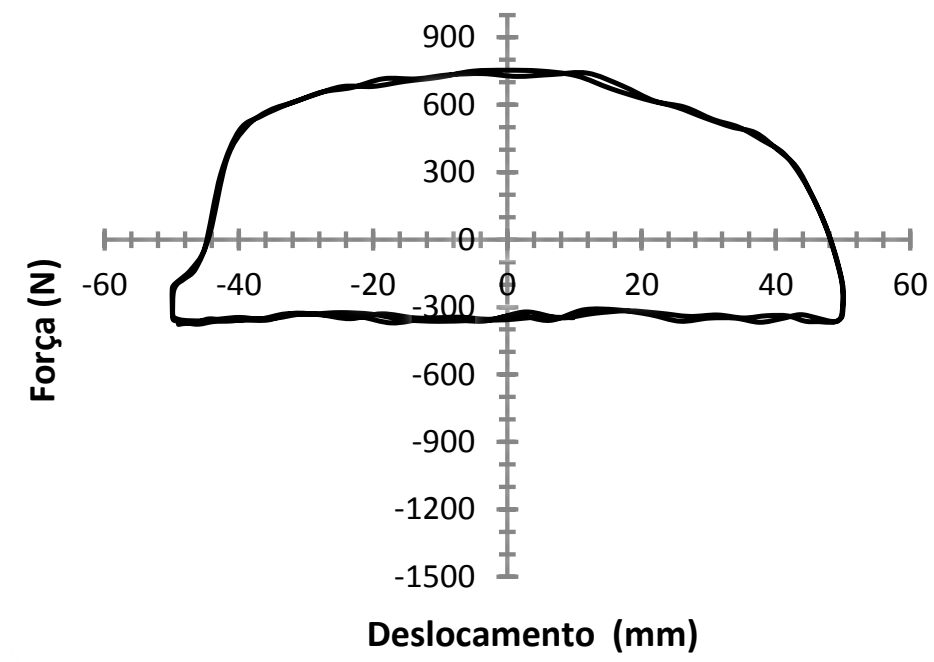

Dessa forma, analisando os dados ilustrados na Figura 6, pode-se notar uma perda de $350 \mathrm{~N}$ na compressão e uma perda menos significativa na extensão em torno de $150 \mathrm{~N}$. As demais amostras de amortecedores remanufaturados obtiveram o seguinte comportamento:

- REC 2 - vazamento de óleo devido ao rompimento do selo à $74^{\circ} \mathrm{C}$ e aos $10 \mathrm{~min} 46 \mathrm{~s}$ de ensaio;

- REC 3 - vazamento de óleo devido ao rompimento do selo à $83^{\circ} \mathrm{C}$ e aos $14 \mathrm{~min} 57 \mathrm{~s}$ de ensaio; 
- REC 4 - vazamento de óleo devido ao rompimento do selo à $85^{\circ} \mathrm{C}$ e aos $17 \min 04 \mathrm{~s} \mathrm{de}$ ensaio.

A Figura 7 apresenta as fotos de algumas amostras onde está destacado o rompimento do selo de vedação durante o ensaio do bloqueio hidráulico.

Figura 7. Foto das amostras REC 1 e REC 2 onde está em destaque (vermelho) o rompimento do selo de vedação.
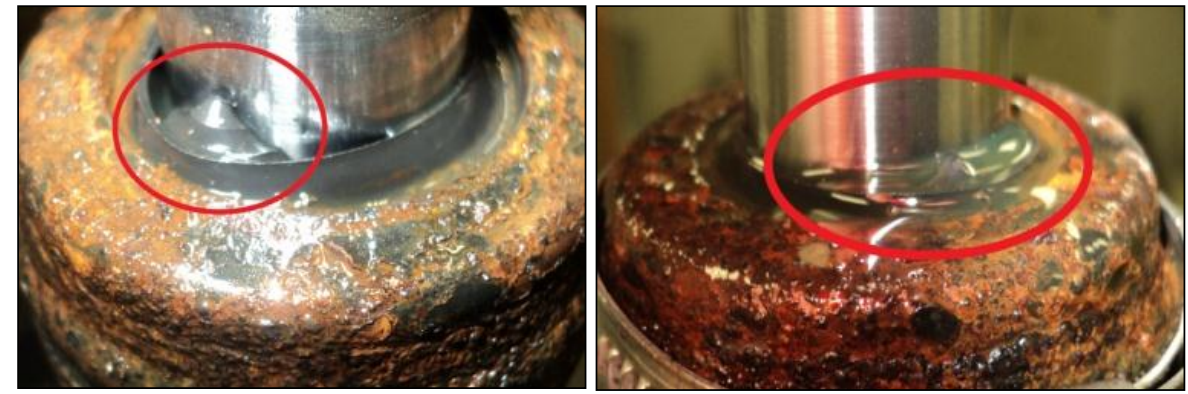

Os amortecedores novos foram testados na mesma sequência de temperaturas das amostras de amortecedores recondicionados. As curvas do ensaio realizado a 30,60 e $90^{\circ} \mathrm{C}$ estão apresentadas respectivamente nas Figuras 8, 9 e 10.

Figura 8. Comparativo dos resultados obtidos no ensaio de bloqueio hidráulico a $30^{\circ} \mathrm{C}$ para as amostras novas.

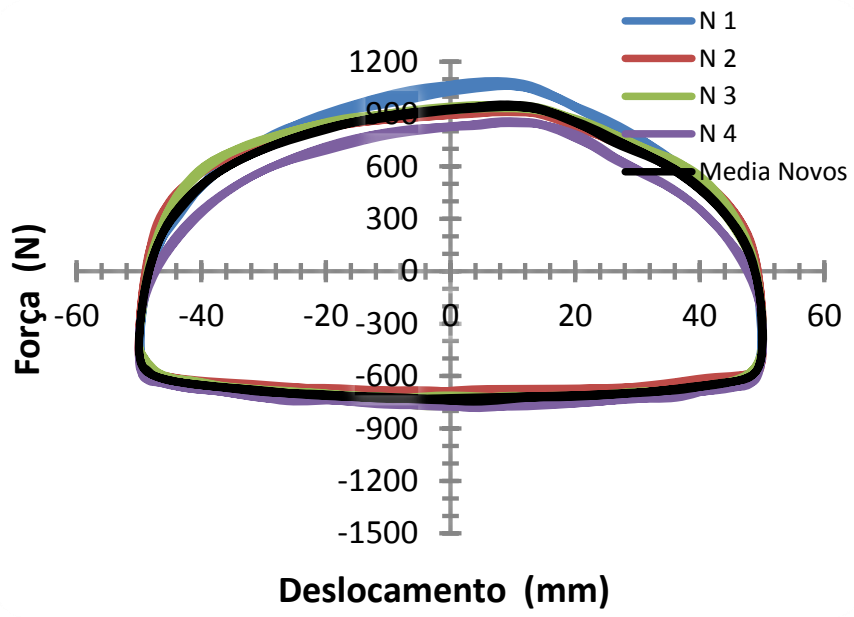

Nas amostras de amortecedores novos não foi observada uniformidade durante o teste de bloqueio hidráulico. As amostras N2 e N3 apresentaram comportamento similar, enquanto que a amostra $\mathrm{N} 1$ obteve um pico de $1100 \mathrm{~N}$ no final da fase de extensão e, a amostra N4 não ultrapassou $850 \mathrm{~N}$. Na curva a $60^{\circ} \mathrm{C}$ (Figura 9) parte dos amortecedores novos apresentou uma pequena perda de desempenho no ciclo de extensão durante o ensaio. As amostras N1 e N4 sofreram uma perda em torno de $100 \mathrm{~N}$ e $200 \mathrm{~N}$, respectivamente. As amostras N2 e N3 mantiveram praticamente o mesmo desempenho observado a $30^{\circ} \mathrm{C}$ (Figura 8). Para esta temperatura a força na fase de compressão praticamente não alterou.

A execução dos ensaios de bloqueio hidráulico à temperatura de $90^{\circ} \mathrm{C}$ (Figura 10) ocasionou uma perda da força no final de extensão em torno de $350 \mathrm{~N}$, quando comparada ao início do 
teste a $30^{\circ} \mathrm{C}$ (Figura 8). A amostra $\mathrm{N} 1$ sofreu uma perda de força menor $(\sim 150 \mathrm{~N})$ e as amostras $\mathrm{N} 2$ e $\mathrm{N} 3$ registraram maior uniformidade durante todo o teste com uma perda em torno de $100 \mathrm{~N}$. Na fase de compressão, os resultados permaneceram estáveis e similares a curva para o ensaio de bloqueio hidráulico obtida para $30^{\circ} \mathrm{C}$.

Figura 9. Comparativo dos resultados obtidos no ensaio de bloqueio hidráulico a $60^{\circ} \mathrm{C}$ para as amostras novas.

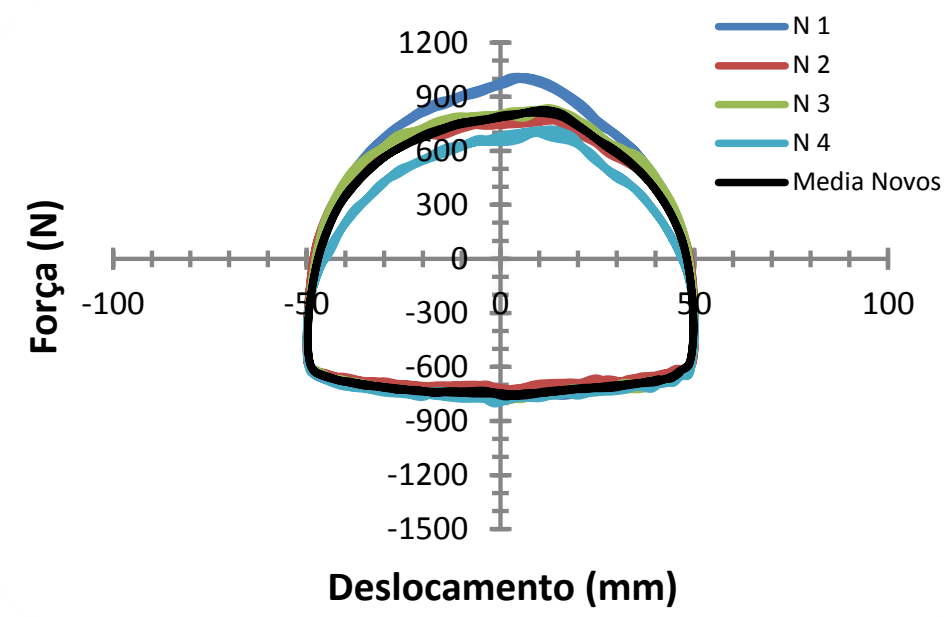

Figura 10. Comparativo dos resultados obtidos no ensaio de bloqueio hidráulico a $90^{\circ} \mathrm{C}$ para as amostras novas.

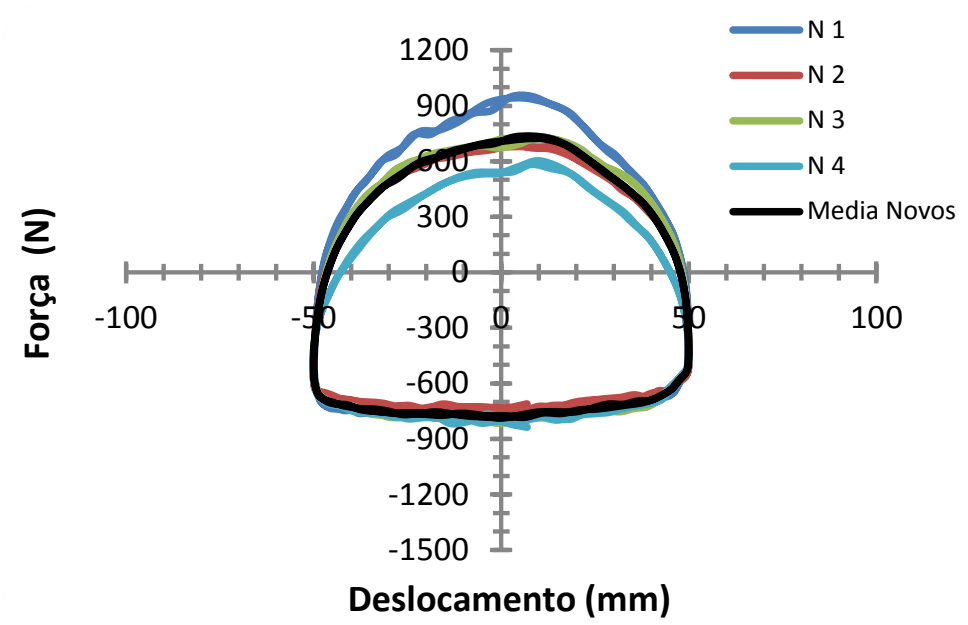

De uma forma geral, pode-se dizer que, no esforço de extensão do amortecedor, o desempenho das amostras teve um comportamento bastante similar mas não uniforme entre as amostras, com a média da força obtida (um pouco abaixo de $800 \mathrm{~N}$ ).

Apesar das amostras novas não registrarem um comportamento similar durante o teste de bloqueio hidráulico, todas as amostras foram aprovadas no requisito 9 da norma ABNT NBR 13308. 


\section{CONCLUSÃO}

Após a realização dos ensaios segundo alguns critérios da norma ABNT NBR 13308 , conclui-se que no ensaio de exposição acelerada à corrosão nenhum dos amortecedores ensaiados conseguiu atender na integra os requisitos do item 7 da norma, com no máximo 10 pontos de corrosão, sendo observado mais de 5\% da área externa comprometida.

No item 9 da norma ABNT NBR 13308 (Ensaio de verificação do bloqueio hidráulico) todas as amostras de amortecedores remanufaturados foram reprovadas. Uma causa que geralmente leva a esta ocorrência é o excesso de óleo adicionado no amortecedor durante a montagem, fato comum a empresas reconcidonadoras que muitas vezes não possuem um controle estatístico do volume a ser inserido em cada modelo de amortecedor. A consequência do excesso de óleo na câmara do amortecedor acentuasse com o aumento de temperatura a que o amortecedor é submetido ocorrendo à expansão volumétrica e o rompimento do selo. Outro fato bastante comum entre estas empresas é o tipo de óleo utilizado no reabastecimento, cuja viscosidade nem sempre é levada em conta. Estas afirmações poderiam ser evidenciadas com estudos mais específicos nos amortecedores remanufaturados testados, onde além do cálculo do volume correto de óleo o estudo abrangeria a viscosidade correta para cada aplicação. Contudo, os amortecedores novos ensaiados apresentaram desempenhos satisfatórios no item, com atendimento aos requisitos desta norma.

Este trabalho tem o cunho de alertar os consumidores que compram amortecedores em lojas de autopeças sobre o risco de enfrentar problemas de manutenção logo após as peças serem substituídas. Devemos sempre buscar comprar itens de reposição com procedência ou certificação. A não atenção a estes requisitos pode levar o consumidor ao risco de acidente na condução do veículo podendo inclusive comprometer a integridade física do condutor e passageiros.

\section{AGRADECIMENTOS}

Os autores agradecem ao Senai Cimatec por disponibilizar o Laboratório de Ensaios Dinâmicos (LED), ao Msc. Luciano Azevedo (Gerente da Área de Mobilidade) por apoiar a iniciativa, a Luara Miranda, Thiago Soriano e Leandro Chrispim por todo apoio prestado, o que tornou possível esta publicação.

\section{REFERÊNCIAS}

[1] História do amortecedor, disponível em http://www.sa-tennecoautomotive.com/Brasil/pdf/manual_amortece dor.pdf; Acesso em 11/04/12.

[2] Nakata Amortecedores, disponível: http://www.nakata.com.br/default.asp?pt=dicas; Acesso 11/04/12.

[3] Sindicato Nacional da Indústria de Componentes para Veículos Automotores, disponível em:http://www.sindipecas.org.br/paginas_NETCDM/modelo_detalhe_generico.asp?ID_ CANAL=17\&id=38498; Acesso 08/05/13. 
[4] BASTOS, Tiago Jorge; Geografia da mortalidade no trânsito no Brasil, 2011, 150f São Carlos, SP, TCC Mestrado - Universidade Federal de São Carlos.

[5] SCHAEFFER, Roberto; SZKLO, Alexandre Salem. Matriz energética de Minas Gerais 2007-2030. Brasil: Ppe/Coppe/Ufrj, 2007.

[6] Instituto Nacional de Metrologia, Normalização e Qualidade Industrial - INMETRO http://www.inmetro.gov.br/legislacao/rtac/pdf/RTAC001718.pdf; Acesso em 17/04/2012.

[7] PALACIO, José; IQA - Instituto da Qualidade Automotiva.

http://www.iqa.org.br/website/artigo_exibe.asp?n=1782, Acessado em 02/05/2012.

[8] Norma Brasileira, ABNT NBR 13308 :2010 - Veículos rodoviários automotores Amortecedor da suspensão - Verificação de desempenho e durabilidade - Método de ensaio, segunda edição (28/04/2010).

[9] Norma Brasileira, ABNT NBR 8094:1983 Material metálico revestido e não revestido Corrosão por exposição à névoa salina - Método de ensaio (1983). 